Dear Dr. Palmer

You have successfully opened page proofs of your chapter and the frontmatter. Please:

- Check carefully for typographical errors and misspellings.

- Respond to any queries from the copyeditor, summarized in the Author Query page and flagged in the proof margin (via AQ or AU).

- If a "poor art quality" notice appears, provide a replacement graphic saved at a higher resolution (300 dpi for photos; 900 dpi for drawings or graphs). Note that the art quality in your PDF proofs does not reflect final print quality.

- Review the Author Information Sheet for accuracy and make necessary changes. This is a summary of important information about you to be used in the book itself, to distribute complimentary copies, and in advertising materials.

- Review the Index Terms selected for your chapter, adding any additional terms you feel are necessary for the reader to locate important information in your chapter.

- Review the frontmatter closely and make any changes to your name/affiliation.

Please send corrections to your chapter and the Author Information Sheet via email or fax.

- Via email: Cite the line number and briefly explain the required correction. Some examples:

Line 17: Should read "In light of recent developments,"

Lines 127, 129, 131-132: Spelling should be "contraindications." Happens 4 times.

Line 216: Reference cited should be 26.

AQ 1: Okay as edited.

AIS: Correct zip code in the mailing address to 10562.

Index terms: Add the following:

Causes of acromegaly, 50-54

Carney complex, 51

McCune-Albright syndrome, 51

Hypertension, 58-60

Overtreatment with growth hormone, 53-54

- Via fax: Print your chapter and mark corrections directly on the proofs. Fax to our USA office: $914-762-4558$.

If you have questions or need assistance, please contact us via return email.

Thank you.

Santype International for

Taylor and Francis Books

Santype International, Inc.

E-mail: TandF_Calhoun@Santype.Com

Fax: 914-762-4558 


\title{
Amplification and the Geriatric Patient
}

\author{
Catherine V. Palmer Amanda Ortmann \\ Author Queries \\ Q1 AU: Please check change made to caption. \\ Q2 AU: Pl. provide caption and citation for Fig. 3. \\ Q3 AU: In References section, pl. provide further details in Ref. 1. \\ Q4 AU: In References section, pl. provide vol. in Ref. 30. \\ Q5 AU: Pl. check if change of the section from ANNOTATED REFERENCES to \\ ANNOTATED BIBLIOGRAPHY is ok.
}




\title{
Amplification and the Geriatric Patient
}

\author{
Catherine V. Palmer \\ Communication Science and Disorders, University of Pittsburgh, and Audiology and \\ Hearing Aids, University of Pittsburgh Medical Center, Pittsburgh, Pennsylvania, U.S.A.
}

\begin{abstract}
Amanda Ortmann
Audiology and Hearing Aids, University of Pittsburgh Medical Center, Pittsburgh, Pennsylvania, U.S.A.
\end{abstract}

\section{GENERAL DESCRIPTION OF THE CLINICAL PROBLEM}

Improvements in technology and medicine over the past 50 years have resulted in significant increases in life expectancy. Twelve percent of the U.S. population was over the age of 65 in 2000; by 2050 that figure will nearly double (1). Along with the shifts in the demographics, there also will be a shift in the health status, with an increase in the number and severity of chronic health conditions affecting the population (2).

Hearing loss is the third most commonly reported chronic condition within the geriatric population (behind arthritis and hypertension) (2). According to the National Center on Deafness and Other Communication Disorders, 33\% of the population over the age of 60 has hearing loss, increasing to $50 \%$ of those over 80 (3). Eight out of 10 residents of nursing homes suffer from hearing loss (4). Although hearing impairment is a prevalent problem among the elderly, only $20 \%$ of those affected actually use hearing aids (5). This is in remarkable contrast to visual impairment; $93 \%$ of the elderly population with visual problems wear glasses routinely (6). The sequellae of uncorrected hearing loss are very similar to those of visual impairment: decreased mobility, social isolation, and depression (7). Hearing aids and other assistive devices provide significant improvement of not only hearing function, but also of the overall quality of life of the elderly individual.

\section{WHY IS HEARING LOSS PARTICULARLY IMPORTANT IN THE GERIATRIC POPULATION?}

Currently, aging adults account for $43 \%$ of the hearing-impaired population (8). As the median age of Americans rise, an increase in the prevalence of hearing loss is to be expected. Health care professionals can assist with the needs of their elderly patients by understanding the nature, repercussions, and remediation of hearing disorders. 
Sensory impairments can limit the quality of life for both elderly individuals and their families. Uncorrected hearing loss leads to reduction of functional, psychological, and psychosocial well-being (9-11). Studies by Mulrow and colleagues (12) as well as Weinstein and Ventry (13) have found that even a mild to moderate hearing loss has a considerable effect on social and emotional handicaps $(12,13)$. The elderly individuals judge the hearing handicap as being less severe than their spouse or partner (14). Thus, family members are often first to recognize the problem of the individual's hearing loss and encourage the use of amplification. Telephone communication often becomes an important link to family and safety as mobility is reduced with aging, with a concomitant requirement for amplification.

There is early evidence that uncorrected hearing loss may contribute to cognitive dysfunction (15). Uhlmann and colleagues (16) examined the relationship between hearing impairment and dementia and found that the prevalence of hearing impairment was higher in the demented adult sample than a comparable sample of adults free from dementia. Dementia and hearing loss interact to produce a more rapid cognitive decline in elderly individuals (17).

Management of hearing loss in the demented population is problematic (18). Although viewed by health care professionals as being hard to test and manage, these patients may often benefit from evaluation and amplification (19).

\section{BASIC SCIENCE}

Presbycusis disrupts both the peripheral and central portions of the auditory system (20). The peripheral loss of hair cells results in decreased audibility of the acoustic signal, particularly in the higher frequencies beyond $2000 \mathrm{~Hz}$. The consonant properties of speech such as the "s," "sh," "f," "t," and "p" have acoustic energy within the range of $2000-8000 \mathrm{~Hz}$ and are therefore "dropped." Vowel properties of speech are preserved; hence, aging adults typically state that they hear conversations, but cannot understand what is being said.

The central component of presbycusis results in a degradation of the rapid processing of speech information, the ability to localize, and the ability to use binaural cues, and increases in severity with increasing age $(21,22)$. Binaural cues are critical for separating speech from background noise. The elderly patient will often have difficulty understanding speech in the presence of background noise due to the central effects of aging, even in the presence of adequate amplification. An aural rehabilitation program should include not only amplification but also education regarding the use of various communication strategies, assistive listening devices (ALDs), and assertiveness (“speak up!”).

\section{HISTORY}

Figure 1 displays a typical audiogram and word recognition results of an elderly individual. Hearing function is similar in both ears with normal or near-normal lowfrequency hearing and decreased hearing sensitivity in the higher frequencies. This individual notes that this hearing loss has a negative effect on communication abilities and lifestyle. The audiogram suggests that the individual is a candidate for an aural rehabilitation program. However, more information (history) about the individual is required in order to select the proper amplification device and counseling strategies. 


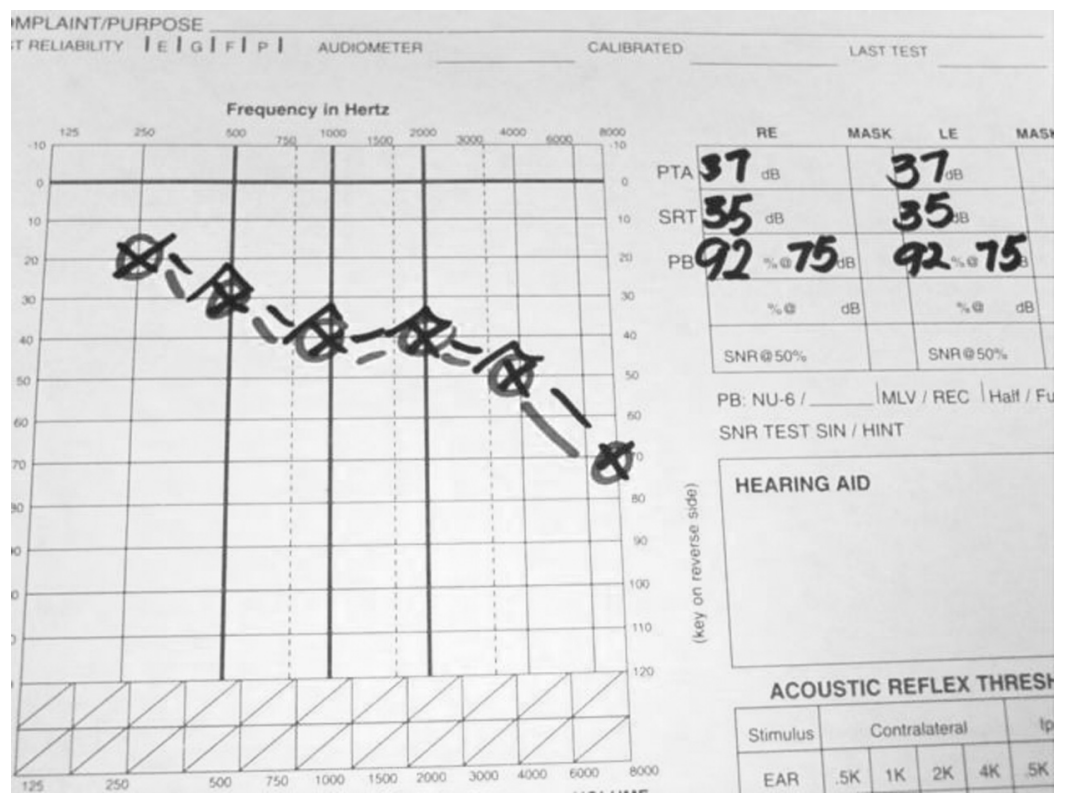

Figure 1 Audiogram of a typical aging hearing loss.

Physical, psychosocial, or psychological changes associated with aging influence the auditory testing procedures and the aural rehabilitation design and outcome (10). Foremost among the physical changes that can interfere with the aural rehabilitation program are the individual's overall general health, visual deficits, and dexterity. Both advanced age and concomitant disease(s) may influence the individual's motivation and acceptance of the aural rehabilitation program. Manipulation of a hearing aid or other assistive listening device requires visual acuity and fine motor skills. Although not a contraindication, vision loss and decreased dexterity must be considered in the context of the aural rehabilitation program.

Cerumen production is a challenging physical change that impacts aural rehabilitation, as it can lead to malfunctioning of hearing aids by blocking the receiver opening in certain instruments. Some elderly hearing aid users require routine cerumen removal.

A major psychosocial change in aging adults that affects the aural rehabilitation program is the reduction of social activity. This reduction may or may not be the direct result of hearing loss. In order to be motivated to participate in a program designed to improve communication function, the aging individual must be involved in meaningful social interactions. Hearing-impaired adults experience some degree of social isolation and often require encouragement to seek increased social activities as part of their rehabilitation program.

Psychological changes such as cognitive decline and depression also can influence the diagnosis and treatment of hearing impairment in the elderly population. Hearing loss has been associated with a sense of helplessness, passivity, and negativism (23). These negative emotions will influence the aging patient's acceptance of the hearing aids. Aging individuals may need a longer timeframe to learn and retain new information (24). 


\section{PHYSICAL EXAMINATION}

A case history is an integral component of every audiologic and/or hearing aid evaluation. It consists of specific questioning regarding hearing, tinnitus, balance function, situational performance, and general health. Otoscopy is performed with particular attention to ear texture and elasticity and checking for collapsing ear canal openings. These findings impact the choice of earphones for audiometric testing and later impact recommendations related to hearing aid selection and earmold material. The ear canal must be free from debris and the tympanic membrane visible and intact.

\section{TESTING}

\section{Screening}

The onset of presbycusis is subtle, and patients are frequently unaware of their hearing loss and do not seek evaluation of their hearing voluntarily. Routine screening of hearing loss by primary care physicians may be quite helpful in the detection of patients who would benefit from aural rehabilitation. Screening may be accomplished through a handheld device that functions as both an otoscope and an audiometer. For screening purposes, it performs a pure tone sweep across frequencies of $500,1000,2000$, and $4000 \mathrm{~Hz}$ and the patient reports whether tones were heard. Background noise in the examination room must be kept to a minimum. There is some debate as to what intensities and frequencies should be used in the screening protocol to maximize the test's sensitivity and specificity (25).

The use of self-administered questionnaires regarding the patient's hearing handicap in certain situations is a simple and inexpensive approach to screening hearing. The hearing handicap inventory for the elderly-screening version is a 10-item, five-minute questionnaire that measures the degree of social and emotional hearing handicap (26). The American Academy of Otolaryngology devised the five minute hearing test, which is another self-administered questionnaire that can be used for screening purposes (27). These self-reported screening tests assess not only the patient's self-perceived hearing loss but also their motivation for hearing care.

\section{Comprehensive Audiologic Examination}

The routine audiologic test battery consists of pure tone and speech testing, static impedance, and acoustic reflexes. Word recognition scores, used for diagnostic purposes, also play a role in the aural rehabilitation program. If word recognition ability at audible levels is poor, then counseling must include realistic expectations of the results of amplification. Although such a patient will benefit from amplification, they usually must rely more heavily on visual cues and/or assistive listening devices.

A common challenge to rehabilitation in the hearing-impaired population is a reduced dynamic range, referring to the range between the thresholds of audibility and loudness discomfort. In age-related hearing loss, the elevated threshold of audibility contributes to the reduction of the dynamic range. The relationship between the change in audibility threshold and loudness discomfort level, however, is not linear due to recruitment. Recruitment is abnormal loudness gain for suprathreshold stimuli. In other words, sounds increase from very soft to uncomfortably loud rapidly with increasing stimuli. Determination of the elderly individual's loudness 
discomfort level when fitting a hearing aid or any other type of assistive listening device is important to ensure that the maximum output of the hearing aids does not exceed this level.

A salient characteristic of the elderly hearing-impaired listener is the decreased understanding of speech in the presence of background noise. In a study by Frisna and Frisna (28), a group of younger listeners and a group of elderly listeners with equivalent audiometric sensitivity completed a variety of speech recognition tasks in quiet and in background noise. It was found that although the elderly group's hearing sensitivity did not differ from the younger listeners, they performed significantly worse on speech recognition tasks in background noise than their younger counterparts. There are several speech recognition tests that quantify the difficulty the elderly patient is likely to experience with background noise, such as the hearing in noise test (HINT), and a shortened version of the speech in noise test (QUICKSIN). Performance on these tests may help guide the aural rehabilitation program.

\section{TREATMENT OPTIONS}

Testing is completed when the type, degree, and configuration of the hearing loss is defined for each ear separately; the individual's ability to understand words in quiet and in noise is documented; and the elderly individual's communication needs, challenges, and expectations are understood in the context of the individual's communication environment. All patients who exhibit a hearing loss, regardless of the severity, are candidates for an aural rehabilitation program and/or amplification. The aural rehabilitation program can be divided into four sections (Table 1): the selection of hearing aids or other listening devices (this session is called the hearing aid evaluation), the hearing aid fitting, orientation, and counseling.

During the hearing aid evaluation, many decisions regarding hearing aid features need to be made. Table 2 contains a list of all of the up front decisions that the elderly individuals, their family, and the audiologist need to consider. The following sections focus on five of the major considerations. These include style of hearing aid, hearing in noise, signal processing, use of the telephone, and safety.

Table 1 Four Components of an Aural Rehabilitation Program

\begin{tabular}{|c|c|c|c|}
\hline $\begin{array}{l}\text { Hearing aid selection } \\
\text { and evaluation }\end{array}$ & Hearing aid fit & Hearing aid orientation & $\begin{array}{l}\text { Counseling and } \\
\text { training }\end{array}$ \\
\hline Selection & Verification & Insertion and removal & Expectations \\
\hline $\begin{array}{l}\text { Monaural versus } \\
\text { binaural }\end{array}$ & Validation & Care and maintenance & $\begin{array}{l}\text { Communication } \\
\text { strategies }\end{array}$ \\
\hline $\begin{array}{l}\text { Omnidirectional } \\
\text { versus directional } \\
\text { microphones }\end{array}$ & & $\begin{array}{l}\text { Use of volume control } \\
\text { and/or memory push } \\
\text { button }\end{array}$ & $\begin{array}{l}\text { Understanding the } \\
\text { hearing aid features }\end{array}$ \\
\hline Hearing aid style & & $\begin{array}{l}\text { Use of hearing aid } \\
\text { programs } / \text { memories }\end{array}$ & Listening practice \\
\hline \multicolumn{4}{|l|}{ Telecoil } \\
\hline \multicolumn{4}{|l|}{ Signal processing } \\
\hline Use of other ALDs & & & \\
\hline
\end{tabular}


Table 2 Up Front Considerations That Must Be Made Prior to Ordering the Hearing Aid

Style of hearing aid

Monaural versus binaural amplification

Microphone type

Earmold type, earmold length, earmold venting

Sound channel characteristics

Bandwidth of the instrument

Receiver type

Output limiting

Volume control

Batteries (battery door locks)

Signal processing

Number of signal processing channels

Multimemory

Ability to fine tune (programmable)

The decisions are made based on empirical evidence, audiologist experience, and patient and family preference.

\section{Hearing Aid Style}

The common styles of hearing aids are behind the ear (BTE), in the ear (ITE), in the canal (ITC), and completely in the canal (CIC) (Fig. 2). In selecting the style (or the size) of the hearing aid, the audiologist must consider the individual's dexterity, ear canal size and texture, history of cerumen accumulation, and degree of hearing loss.

The BTE hearing aid has the most flexibility. BTE hearing aids have much more room for circuitry and options. The size and shape of the ear canal does not



Figure 2 Four styles of hearing aids (clockwise from bottom left): behind the ear, in the ear, AQ1 in the canal, completely in the canal. 


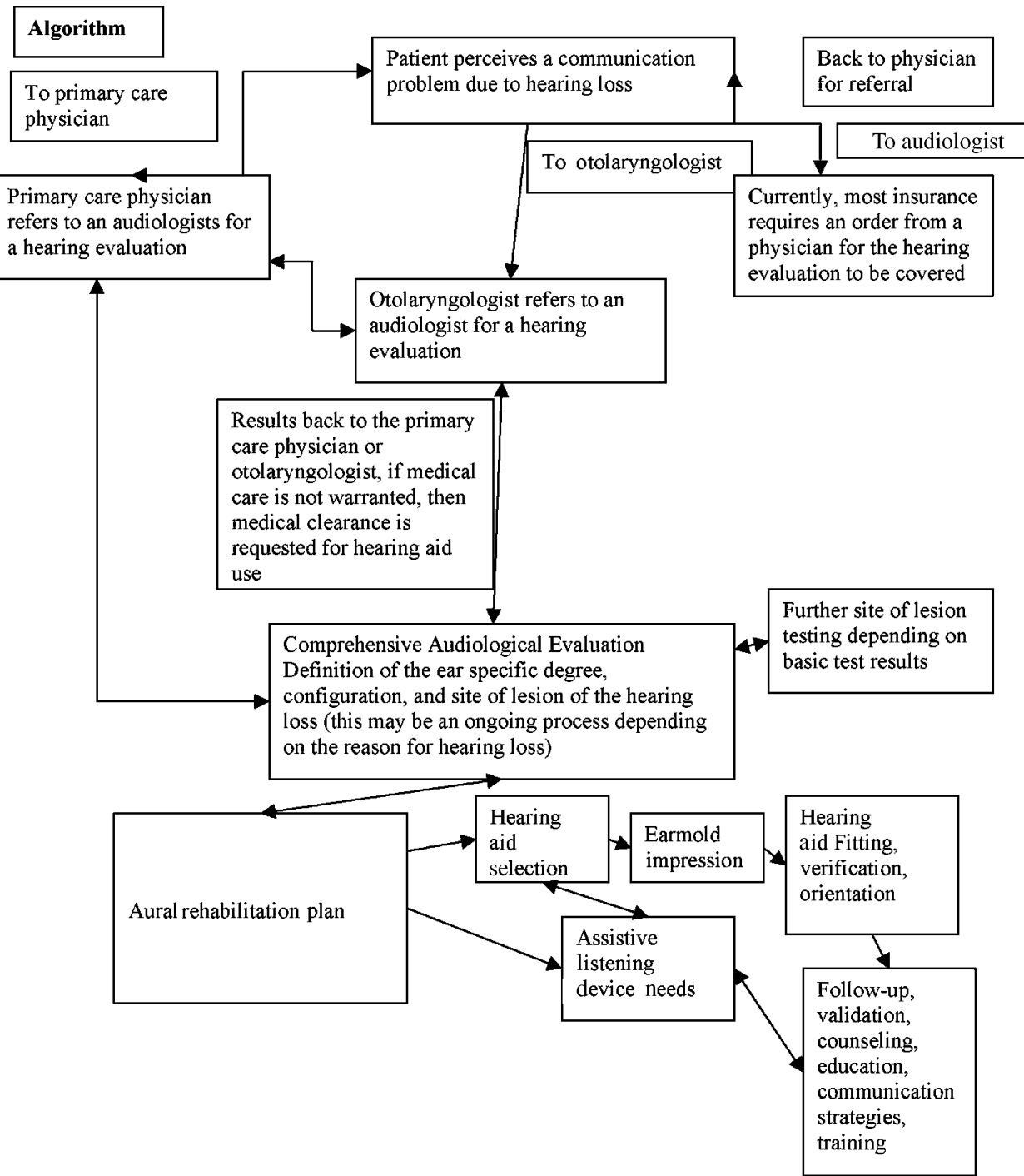

Figure 3

interfere with the choices of hearing aid options for the patient. BTEs can provide the necessary gain to accommodate hearing losses ranging anywhere from mild to profound. BTE hearing aids are coupled to the ear with an earmold. By making specific changes to the earmold (length of tubing, belling of sound bore, vent sizes, etc.), a particular frequency/gain enhancement can be created. Patients usually report that these acoustic modifications sound more natural than electronic modifications accomplished through hearing aid circuitry. Other advantages of having a standard hearing aid coupled to a custom earmold include the ability to attach a loaner hearing aid to the user's earmold should the hearing aid need repair or service.

Another advantage of BTE hearing instruments is that care and maintenance is less problematic than with other types of hearing aids. With custom hearing aids that fit completely inside the ear canal and concha, the electronics, particularly the 
receiver, are vulnerable to cerumen blockage and damage from heat and moisture. Because the electronics of the BTE hearing aid are housed external to the ear canal, it is not vulnerable to these elements found in the ear canal. The earmold can accumulate cerumen blockage, but the patient simply brushes away the visible cerumen or disconnects the earmold from the hearing aid to soak the mold in a cup of warm water. If the elderly patient has a history of cerumen accumulation, a BTE hearing aid should be considered. Insertion, removal, and manipulation (changing the battery) of BTE instruments are relatively easy. Because it is bigger, it may be beneficial to an elderly individual who experiences problems with manual dexterity. Some patients find the bulkiness of this hearing aid a drawback to its use. However, with appropriate hair styling this aid can be very discreet. The earmold is made of a translucent plastic that blends in with the skin tone of the patient and the hearing aid portion is tucked neatly behind the ear.

ITE and ITC hearing aids are limited in their flexibility due to space limitations. A patient's ear canal may be too small to accommodate certain options such as a telecoil or directional microphones. These hearing aids typically fit a hearing loss range of mild to moderate. Due to the close proximity of the microphone and receiver, these hearing aids are more vulnerable to feedback, especially if the hearing loss is more severe. Feedback occurs when amplified sound "feeds" back into the microphone to be reamplified. Proper fit of these custom products is imperative.

Manipulation of these custom hearing aids may be more difficult for the elderly patient. The batteries in these hearing aids may be smaller in size and are not appropriate for someone with poor visual acuity and/or manual dexterity. However, several modifications can be made to reduce problems due to dexterity. A removal string can be added to ITE or ITC hearing aids for easier removal of the instrument from the ear. The volume control wheel can be stacked, making it more pronounced for easier manipulation. In some of the more advanced technology, the audiologist is able to enable and disable the volume control. This feature is very useful if you find an aging patient who is confused by the volume control. Rather than send the hearing aid back to have the volume control removed, it simply can be disabled.

There are individual differences in manipulation. For some older adults, insertion of one piece (the ITE) is easier than the two-piece BTE, which requires an extra step of looping the hearing aid behind the ear.

A CIC hearing aid may be the least visible of all the hearing instruments. A CIC hearing instrument fits deeply inside the patient's ear canal. The goal of a CIC is to take advantage of the acoustic properties of the external ear. However, it is not the best recommendation for an elderly individual for a number of reasons. It is the most limited in terms of flexibility and only can amplify hearing losses in the mild-to-moderate range. There is no space for any additional options. Because of deep insertion, it is more prone to cerumen blockage, therefore requiring more cleaning and maintenance on the patient's part. For the elderly patient, extra visits into the clinic for repairs and frequent cerumen removal may be very difficult. If a CIC is used, a wax guard system that the individual can replace on their own in order to avoid hearing aid repairs should be considered. The CIC is likely to be more difficult to insert for the elderly patient. The battery size is very small, so routine manipulations such as changing the battery are more difficult.

There may also be issues of occlusion effect with the CIC instruments. The occlusion effect is said to occur when patients state that their own voice sounds "hollow" or "in a barrel" due to the hearing aid occluding the ear canal. This effect is typically solved by venting the hearing aid or earmold so that the user does not 
Table 3 Pros and Cons of Hearing Aid Styles

\begin{tabular}{|c|c|c|c|c|}
\hline & BTE & ITE & ITC & CIC \\
\hline $\begin{array}{l}\text { Flexibility- } \\
\text { hearing loss } \\
\text { fitting range }\end{array}$ & $\begin{array}{l}\text { Mild to } \\
\text { profound }\end{array}$ & Mild to severe & Mild to severe & Mild to moderate \\
\hline $\begin{array}{l}\text { Flexibility- } \\
\text { number of } \\
\text { options }\end{array}$ & Very flexible & $\begin{array}{l}\text { Dependent on } \\
\text { size of ear } \\
\text { canal }\end{array}$ & $\begin{array}{l}\text { Dependent of } \\
\text { size of ear } \\
\text { canal }\end{array}$ & No options \\
\hline Manipulation & Easy & Can be difficult & Can be difficult & Difficult \\
\hline $\begin{array}{l}\text { Care and } \\
\text { maintenance }\end{array}$ & Minimal & $\begin{array}{l}\text { Problems with } \\
\text { earwax } \\
\text { blockage }\end{array}$ & $\begin{array}{l}\text { Problems with } \\
\text { earwax } \\
\text { blockage }\end{array}$ & $\begin{array}{l}\text { A significant } \\
\text { problem with } \\
\text { earwax } \\
\text { blockage }\end{array}$ \\
\hline Cosmetic & $\begin{array}{l}\text { Depends on } \\
\text { hairstyle }\end{array}$ & Visible & Less visible & Least visible \\
\hline
\end{tabular}

Abbreviations: BTE, behind the ear; ITE, in the ear; ITC, in the canal; CIC, completely in the canal.

feel so "plugged up" by the hearing aid. Due to the small size of a CIC hearing aid, adequate venting is not possible.

Selection of hearing aid style will be influenced by patient preference. Some patients will have a preconceived notion of what hearing aid style they want. It is important that the audiologist and patient compromise a few features and options in order to select an amplification device that the individual will wear. If the patient is forced to purchase an undesirable hearing aid style, then the hearing aid may not be used at all. The best hearing aids are the ones that the patient will wear. Table 3 is a comparison of hearing aid styles highlighting their pros and cons for the aging adult.

\section{Hearing in Noise}

An estimated $25 \%$ of hearing aid users are not wearing their hearing aids due to the negative effects of background noise (29). Due to the nature of age-related hearing loss, simple amplification is inadequate to provide maximum intelligibility in noise. Some of the solutions include binaural amplification, directional microphone technology, noise reduction circuitry, and the use of assistive listening devices.

\section{Binaural Amplification}

A significant advantage of binaural hearing is noise suppression since two ears are necessary to efficiently separate the speech signal from surrounding background noise (30). Binaural amplification provides the user with a $2-3 \mathrm{~dB}$ signal-to-noise ratio enhancement (31). It is critical to the success of the aural rehabilitation program to do everything possible to enhance the signal-to-noise ratio; hence, binaural amplification should be recommended and encouraged for most patients with presbycusis.

In 1980, Dirks and Wilson (32) noted that sounds presented binaurally are perceptually $3 \mathrm{~dB}$ louder than the actual level due to binaural summation. This is advantageous in that less gain is needed to achieve the same perception of loudness, resulting in less feedback. In addition to noise suppression and binaural summation, binaural hearing is critical to sound localization via comparison of the intensity and temporal cues from each ear individually. Binaural amplification aids the user's 
ability to localize sound, which may be important for the safety of the elderly individual in certain situations. Binaural interference is a phenomenon that occurs in some elderly patients who exhibit a large asymmetry in word recognition scores between the right and left ear and is a relative contraindication for binaural amplification (33). Word recognition scores should be tested individually and binaurally. If the binaural word recognition score is significantly poorer than that of the better ear, then binaural amplification may be inappropriate.

\section{Directional Microphones}

Directional microphones to improve performance in noise have been recently introduced and may benefit some individuals (34-37). All hearing aids dispensed have an omnidirectional microphone, which collects sounds from any directional source and passes them through to the amplifier without relative delay. A hearing aid with a directional microphone involves the use of an additional rear-facing microphone. Input from the additional rear microphone is delayed so that the signal from behind the person is cancelled. Thus, in a directional microphone hearing aid, sounds in front of the wearer are amplified, but the sounds behind them are attenuated. This type of technology has been shown to provide significant improvement in the presence of background noise, provided that the noise is behind the patient and the signal is in front. The magnitude of the cancellation effect of the directional microphones increases as the listening environment becomes more unfavorable, even with the level of the noise being louder than the level of speech (34).

Hearing aids that have directional microphone technology are equipped with a push button or a switch so that the user can turn the directional program on and off. In quiet listening environments, the user should have the hearing aid switched to omnidirectional mode so that all sounds are amplified regardless of location. Once the listener enters a noisy situation, such as a restaurant, the user can either press the push button or a switch to change into the directional microphone program. For elderly patients with manual dexterity handicaps, a remote control can be ordered to change between the programs stored in the hearing aid.

Recently, automatic microphone technology has emerged. Automatic microphones switch back and forth between omnidirectional and directional modes automatically based on the sound environment. This technology is advantageous for the elderly population in that it is more hands free. However, the patient can override this automatic directional program by manipulating the push button or remote control. This may be important in situations such as crossing a busy street. The hearing aid will consider this "noisy" and switch into the directional setting, but for safety the individuals may want to hear all around them.

A proper and thorough hearing aid orientation is critical to the use and benefit of directional microphones. The elderly patient has to understand the use of the multiple programs stored in the hearing aid and how to manipulate or change them via the push-button or remote control. In addition, the aging patient needs to understand that they must orient themselves so that the noise is predominantly behind them and the speaker in front of them in order for the directional microphones to be of benefit.

\section{Noise Reduction Circuitry}

Noise, when analyzed spectrally and temporally, has a broad frequency band and is steady state or constant. In contrast, the acoustic properties of conversational speech 
are frequency specific and dynamic. Hearing aid engineers have used these contrasting properties to design noise reduction algorithms that will cancel or reduce steadystate sounds while maintaining the amplification of dynamic stimuli. For example, the sound of an air conditioner fan is a steady-state background noise-its intensity level and frequency band remain constant. A noise reduction circuit will cancel this noise so that it is not amplified by the hearing aid. Although noise reduction circuitry has not been shown to improve user understanding in noise, it may decrease the annoyance of the noise, which could lead to less effort expended in communication situations and/or less fatigue.

\section{Assistive Listening Devices}

Assistive listening devices (ALDs) are a family of instruments that can be either coupled to a hearing aid or used alone to assist the user in awareness and discrimination of speech and environmental sounds. Elderly patients with a profound hearing loss or very poor word recognition scores may need to rely on ALDs for not only maximum speech intelligibility in noise, but for safety concerns as well.

Some ALDs utilize a frequency-modulated radio signal (FM signal) that is coupled directly to the hearing aid via a "boot" (for a BTE hearing aid) or through an electromagnetic neckloop (for a BTE or ITE hearing aid). An FM system consists of an external microphone that is worn by the speaker and transmits the signal to the boot or neckloop. The hearing aid must be set to receive only the FM signal from the microphone or other assistive device such as those used in public places such as churches, concert halls, and theaters. FM systems provide the greatest signal-tonoise ratio enhancement in that the hearing aid only receives what is transmitted from the microphone, which is inches away from the speaker's mouth since the microphone in the hearing aid is disconnected. Other ALDs include amplified telephones, infrared television amplifiers, and various alerting systems. These systems may be vital in ensuring the elderly individual's safety. Smoke detectors, doorbell ringers, and personal paging systems may alert an individual through a visual (flashing light), auditory (louder signal), or tactile (vibration) signal. ALDs may be somewhat cumbersome, so it is important that the most appropriate device be selected for the individual's needs and lifestyle.

\section{Signal Processing}

The basic components of a hearing aid are the microphone, amplifier, and the receiver. The analog electronic signal processing circuit within the amplifier divides the signal into different frequency bands (the number of these bands varies with the complexity of the circuit), which can be manipulated by changing the gain or the output characteristic of each band. These settings are done in the office by coupling the hearing aids to a computer and programming them with the appropriate software.

Within the past decade, there have been many significant changes in the electronic signal processing of the hearing aid with the advent of digital signal processing (DSP). Analog signals are converted to digital signals, which permits a nearly infinite number of possible signal alterations. While analog signal processing is limited to three bands or less for frequency shaping and compression, DSP technology can divide the signal into as many as 20 bands for processing. Thus, DSP technology has much more flexibility than analog technology (38). 
As DSP technology continues to improve, more patients will benefit from the newer technology. Digital hearing aid sales comprised only $7 \%$ of the total number of hearing aid sales in 1998 whereas in 2002, 42.7\% of hearing aid sales were digital technology (39). It is predicted that all hearing aids dispensed will soon be digital.

It is important to understand the relationship between DSP technology and hearing aid user performance. The primary predictor of speech recognition performance is audibility (40). Both analog and digital signal processing circuits have the capabilities to make the acoustic signal audible to the hearing aid user. Valente et al. (41) showed that performance on speech recognition tasks in noise were not significantly different when users were wearing either analog or digital hearing aids. Other research studies have supported this finding (42). Kochin (43) surveyed 500 individuals using DSP technology and 418 controls and found that DSP hearing aids receive an overall higher satisfaction rating. DSP technology also facilitates reduced feedback through feedback cancellation systems, expansion or gain reduction to reduce low-level noise, noise reduction algorithms, and automatic microphone technology.

\section{Use of the Telephone}

The telephone is an integral part of society and in many situations, the telephone may be the only connection between the elderly individual and family members or friends. Hearing aid users can use the telephone by either placing the receiver over the microphone or by activating a telecoil built into the hearing aid. A telecoil is a magnetic coil inside the hearing aid that picks up the electromagnetic field emitted from the receiver of the telephone (and from FM systems with neckloops) and amplifies the signal. Telecoils can be activated by a push button on the hearing aid, which, when pressed will turn off the microphone of the hearing aid and activate the telecoil. For elderly individuals with manual dexterity problems, the telecoil can be activated automatically by placing a telephone receiver directly on top of a hearing aid equipped with an automatic telecoil. The magnet in the telephone automatically switches the internal magnet in the hearing aid that engages the telecoil receiver. Once the phone is removed, the hearing aid will automatically change back to the regular microphone setting. The advantage of the telecoil is that since the microphone of the hearing aid is deactivated, feedback is eliminated when using the telephone. Some elderly individuals are unable to use the telephone with the hearing aid and often benefit from the use of amplified telephones. In order to utilize this option, however, the hearing aid must be removed and then replaced at the end of the telephone conversation.

\section{Severe Unilateral Hearing Loss}

An individual with a nonfunctioning ear along with a normal (or near-normal) hearing ear may experience difficulty localizing, hearing in noise, and hearing when communication is directed to the nonfunctioning side. Many individuals with this condition use a variety of communication strategies and environmental manipulations to accommodate this situation, but some patients will benefit from specific strategies. There are three potential solutions: (i) contralateral routing of signal (CROS) hearing aid, (ii) a bone-anchore hearing aid (BAHA) implanted on the nonfunctioning side, and (iii) a powerful conventional hearing aid in the nonfunctioning ear (transcranial CROS). Solution one is configured with a microphone pick up on 
the nonfunctioning side and the signal is transmitted via a cord or FM signal to a hearing aid case anchored on the normal ear. The signal is routed into the normal ear through an open ear canal fitting so the same ear can receive input normally from the "good" side. Solutions two (BAHA) and three (transcranial CROS) operate on the same principle. The signal is picked up on the nonfunctioning side and is delivered to the normal hearing cochlea via bone conduction.

Elderly patients with unilateral hearing loss may become aware of communication difficulty sooner than one would expect based on the reduced thresholds in the previously normal hearing ear. These individuals may be fully adapted to being a monaural listener and may only want improved performance in the mildly impaired ear rather than pursuing some type of CROS or transcranial solution. An alternative is a binaural contralate routing of signal (BICROS) aid.

\section{Middle Ear Implantable Hearing Aids}

Several middle ear implantable hearing aids have been developed in the past several years. Some of these are partially implantable and others are designed to be fully implantable. The manufacturers of these instruments claim reduced feedback (high-pitched sound when amplified sound reaches the microphone and is reamplified) due to implantation, but the actual results have been varied. One would recommend a trial with traditional binaural amplification prior to recommending this type of instrument for the geriatric patient.

\section{Cochlear Implant}

An individual with severe to profound sensorineural hearing loss is a cochlear implant candidate. Candidacy for implantation is determined through a battery of performance tests and a hearing aid trial. The most common geriatric patient who would be a cochlear implant candidate would be an individual who suffered sudden, severe-to-profound, permanent sensorineural hearing loss as opposed to the individual who has functioned with this type of hearing loss over their lifetime.

\section{Hearing Aid Fitting}

During the hearing aid fitting verification and validation of the hearing aid performance must be measured. This can be accomplished through a Real-Ear ${ }^{\mathbb{R}}$ measurement, which is a probe microphone system that measures the sound pressure level at the eardrum. Real-Ear verification is used to fine-tune the hearing aid until the hearing aid's output falls within this range so that soft sounds are audible and loud sounds are not uncomfortably loud.

Validation ensures that hearing aid performance meets the needs of the patient. This is obtained through the use of subjective questionnaires that look at handicap, disability, and satisfaction with hearing aids (44). The score tells the audiologist how much benefit the patient perceives from the hearing aids.

\section{Hearing Aid Orientation}

The elderly patients and their family members must understand how to use and take care of the hearing devices properly. The orientation session consists of instructions 
Table 4 Orientation Checklist

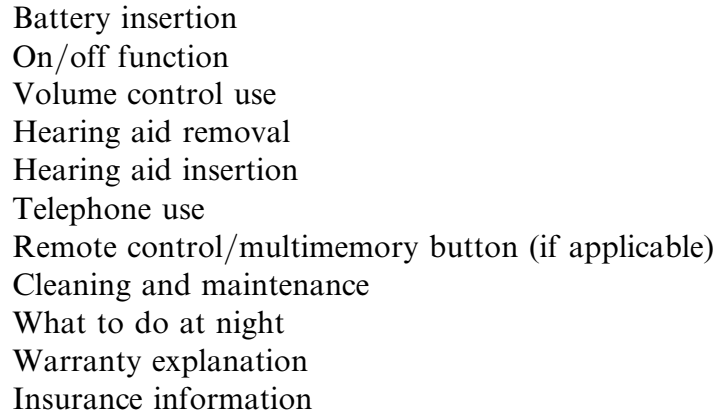

of insertion and removal, how and when to change the battery, how and when to change the hearing aid program designed for listening in background noise, a demonstration of telephone use, etc. (45). Documentation is given to the patient as well as the family or the caretaker. Table 4 provides a checklist of items that should be included in the orientation.

There are a number of helpful accessories for the aging patient such as "Fun Tak $^{\circledR}$ " to hold the hearing aid and an extending magnet to capture batteries that may have fallen or to pick up the whole hearing aid if it has fallen and still has the battery in it. Moisture removal with a dehumidifier kit can add life to the hearing aid and greatly reduce repairs. Repairs may be a larger problem for the older patient who may find it difficult to travel to the clinic repeatedly. Other devices include a line to clip the aid to the shirt collar to reduce the possibility of loss and a battery tab to assist in battery insertion.

\section{Counseling and Training}

The new hearing aid wearer is adjusting to both how the hearing aids feel and how the world sounds and may not like the sound quality until there has been a period of adaptation. Often patients are aware of all sounds such as the sound of shoes on the floor, the refrigerator hum, etc., which creates an uncomfortable sensation. Several weeks are required to accommodate to this new sensation. Kochkin (46) reports that patients received greater satisfaction with their new hearing aids if they were provided with one to two hours of counseling regarding realistic expectation, and the use and care of the hearing aids. Abrahms et al. (47) reported that in a group of aging adults, hearing aid fittings plus aural rehabilitation (counseling) was more cost effective than hearing aid fittings alone.

\section{REFERENCES}

1. NCHS Chartbook on Trends in the Health of Americans, 2002.

2. National Center for Health Statistics. (www.cdc.gov/nchs/)

3. National Institute on Deafness and Other Communication Disorders. (www.nicdcd. nih.gov.)

4. Schow R, Nerbonne M. Hearing levels among elderly nursing home residence. J Speech Hear Res 1980; 45:124-132. 
5. American Speech-Language-Hearing Association. (www.asha.org.)

6. Desai M, Pratt LA, Lentzner H, Robinson KN. Trends in vision and hearing among older Americans. Aging trends No. 2. Hyattsville, Md.: National Center for Health Statistics, 2001.

7. Keller BK, Morton JL, Thomas VS, Potter JF. The effect of visual and hearing impairments on functional status. J Am Geriatr Soc 1999; 47:1319-1325.

8. Jamieson JR. The impact of hearing impairment. In: Katz J, ed. Handbook of clinical audiology. 4th ed. Baltimore: Williams \& Wilkins, 1994:596-615.

9. Carabellese C, Appollonio I, Rozzini R, et al. Sensory impairment and quality of life in a community elderly population. J Am Geriatr Soc 1993; 41:401-407.

10. Palmer CV. Improvement of hearing function. In: Huntley RA, Helfer KS, eds. Communication in later life. Boston: Butterworth-Heinemann, 1995:181-223.

11. Bess FH, Lichtenstein MJ, Logan SA, Burger MC, Nelson E. Hearing impairment as a determinant of function in the elderly. J Am Geriatr Soc 1989; 37:123-128.

12. Mulrow C, Aguilar C, Endicott J, et al. Association between hearing impairment and the quality of life of elderly individuals. J Am Geriatr Soc 1990; 38:45-50.

13. Weinstein B, Ventry I. Hearing impairment and social isolation in the elderly. J Speech Hear Res 1982; 32:593-599.

14. Chmiel R, Jerger J. Some factors affecting the assessment of hearing handicap in the elderly. J Am Acad Audiol 1993; 4:249-257.

15. Gates GA, Karzon RK, Garcia P, et al. Auditory dysfunction in aging and senile dementia of the Alzheimer's type. Arch Neurol 1995; 52:626-634.

16. Uhlmann R, Larson E, Rees T, Koepsell T, Duckert L. Relationship of hearing impairment to dementia and cognitive dysfunction in older adults. JAMA 1989; 261:1916-1919.

17. Peters CA, Potter JF, Scholer SG. Hearing impairment as a predictor of cognitive decline in dementia. J Am Geriatr Soc 1988; 36:981-986.

18. Durrant J, Gilmartin K, Holland A, Kamerer D, Newall P. Hearing disorders management in Alzheimer's disease patients. Hear Instrum 1991; 42:32-35.

19. Palmer CV, Adams SW, Bourgeois M, Durrant, JD, Rossi M. Reduction in caregiveridentified problem behaviors in patients with Alzheimer disease post-hearing-aid fitting. J Speech Lang Hear Disord 1999; 42:312-328.

20. Willott JF. Anatomic and physiologic aging: a behavioral neuroscience perspective. J Am Acad Audiol 1998; 7:141-151.

21. Stach B, Spretnjak M, Jerger J. The prevalence of central presbycusis in a clinical population. J Am Acad Audiol 1990; 1:109-115.

22. Jerger J, Chmial R, Wilson N, Luchi R. Hearing impairment in older adults: new concepts. J Am Geriatr Soc 1995; 43:928-935.

23. Herbst K, Humphrey C. Hearing impairment and mental state in the elderly living at home. Br Med J Clin Res 1980; 281:903-905.

24. Canestrari R. Paced and self-paced learning in young and elderly adults. J Gerontol 1963; 18:165-168.

25. Schow RL. Considerations in selecting and validating an adult/elderly hearing screening protocol. Ear Hear 1991; 12:337-348.

26. Ventry IM, Weinstein BE. Identification of elderly people with hearing problems. ASHA $1983 ; 7: 37-42$.

27. American Academy of Otolaryngology-Head \& Neck Surgery. The five minute hearing test. AAO-HNS Bull 1990; 9:43.

28. Frisna DR, Frisna RD. Speech recognition in noise and presbycusis: relations to possible neural mechanisms. Hear Res 1997; 106:95-104.

29. Kochin S. MarkeTrak V. "Why my hearing aids end up in the drawer": the consumer's perspective. Hear J 2000; 53(2):34,36,39-42.

30. Valente M. Binaural amplification: part II. Audecibel 1984; 10-14. 
31. Hawkins D, Yacullo W. Signal to noise ratio advantange of binaural hearing aids and directional microphones under different levels of reverberation. Speech Hear Disord 1984; 49:278-286.

32. Dirks D, Wilson R. Binaural hearing in sound field. In: Libby ER, ed. Binaural Hearing and Amplification, Vol. 1. Chicago: Zeneron, 1980:105-122.

33. Jerger J, Silman S, Lew H, Chimel R. Case studies in binaural interference: converging evidence from behavioral and electrophysiologic measures. J Am Acad Audiol 1993; 4:122-131.

34. Valente M, Sweetow R, Potts LG, Bingea B. Digital versus analog signal processing: effect of directional microphone. J Am Acad Audiol 1999; 10:133-150.

35. Agnew J, Block M. HINT thresholds for a dual-microphone BTE. Hear Rev 1997; 4(9):26, 29-30.

36. Ricketts T. Impact of noise source configuration on directional hearing aid benefit and performance. Ear Hear 2000; 21:194-205.

37. Ricketts T, Dhar S. Comparison of performance across three directional hearing aids. J Am Acad Audiol 1999; 10:180-189.

38. Agnew J. Amplifiers and circuit algorithms for contemporary hearing aids. In: Valente M, ed. Hearing Aids: Standards, Options, and Limitations. 2nd ed. New York: Thieme, 2002:101-142.

39. Kochkin S. MarkeTrak VI. Ten year customer satisfaction trends in the US hearing instrument market. Hear Rev 2002; 9(10):14-25,46.

40. Humes L, Roberts L. Speech-recognition difficulties of the hearing-impaired elderly: the contributions of audibility. J Speech Hear Res 1990; 33:726-735.

41. Valente M, Fabry DA, Potts LG, Sandlin RE. Comparing the performance of the widex senso digital hearing aid with analog hearing aids. J Am Acad Audiol 1998; 9:342-360.

42. Newman CW, Sandridge SA. Review of research on digital signal processing. In: Valente M, ed. Hearing Aids: Standards, Options, and Limitations. 2nd ed. New York: Thieme, 2002:347-381.

43. Kochin S. Customer satisfaction with single and multiple microphone digital hearing aids. Hear Rev 2000 November:24-34.

44. Cox RM, Alexander GC. The abbreviated profile of hearing aid benefit. Ear Hear 1995; 16:176-186.

45. Mormer E, Palmer C. A systematic program for hearing aid orientation and adjustment. In: Sweetow R, ed. Counseling for Hearing Aid Fittings. San Diego, CA: Singular Publishing, 1999.

46. Kochkin S. Factors impacting consumer choice of dispenser and hearing aid brand; use of ALDs and Computers. Hear Rev 2002; 9(12):12-23.

47. Abrahms H, Chisolm T, McArdle R. J Rehabil Res Dev 2002; 39(5):549-558.

\section{ANNOTATED BIBLIOGRAPHY}

Bogardus ST, Yeuh B, Shekelle PG. Screening and management of adult hearing loss in primary care: clinical applications. JAMA 2003; 289(15):1986-1990.

This is an excellent, comprehensive, critical review of the subject of adult hearing screening.

Campbell K. Essential audiology for physicians. San Diego: Singular Publishing Group, 1997

This text is aimed at the practicing physician and provides good detail related to audiology while being easily read and well organized.

Palmer CV. Improvement of hearing function. In: Huntley RA, Helfer KS, eds. Communication in later life. Boston: Butterworth-Heinemann, 1995:181-223. 
49

50

This chapter provides a great deal of detail regarding modifications to procedures in audiology appropriate for the older adult.

Yueh B, Shapiro N, MacLean CH, Shekelle PG. Screening and management of adult hearing loss in primary care: scientific review. JAMA 2003; 289(15):1976-1985.

This complements the Bogardus et al. (2003) article with scientific underpinnings. 


\title{
Chapter 5
}

\author{
Hearing loss \\ Presbycusis \\ case history \\ hearing handicap inventory for the elderly-screening version \\ five minute hearing test \\ speech recognition tasks \\ Testing \\ aural rehabilitation program \\ hearing aid evaluation \\ hearing aid fitting \\ orientation \\ counseling \\ hearing aid evaluation \\ styles of hearing aids \\ BTE hearing aid \\ ITE hearding aid \\ ITC hearing aid \\ CIC hearing aid \\ intelligibility in noise \\ Binaural amplification \\ Directional microphones \\ Noise Reduction Circuitry \\ Assistive listening devices \\ Signal Processing \\ digital signal processing \\ telecoil \\ analog signal processing

\section{Cochlear Implant} \\ Real-Ear ${ }^{\circledR}$
}


Marcel Dekker, Inc.

ARTICLE / CHAPTER INFORMATION SHEET

\begin{tabular}{|l|l|}
\hline & \\
\hline & \\
\hline Book Authors/Editors: & Calhoun, Eibling, Kost and Wax \\
\hline Book Title: & Geriatric Otolaryngology \\
\hline ISSN/ISBN: Print & $\mathbf{0 - 8 2 4 7 - 2 8 5 0 - 5}$ \\
\hline ISSN/ISBN: Web & Please Provide ISSBN-Web \\
\hline CMS ID number: & Chapter 5 \\
\hline Chapter Title: & Amplification and the Geriatric Patient \\
\hline Article type: & REFERENCE \\
\hline Key words: & Please Provide Keywords \\
\hline Copyright holder: & Please Provide Copyright Holder \\
\hline & \\
\hline & \\
\hline FOR EACH AUTHOR: & \\
\hline & \\
\hline Author Number: & \\
\hline Author first name or initial: & $\mathbf{1}$ \\
\hline Author middle initial: & Catherine \\
\hline Author last name: & V. \\
\hline Suffix to last name: & Palmer \\
\hline Degrees: & \\
\hline Honorific: & Ph.D. \\
\hline Author e-mail address: & palmercv@upmc.edu \\
\hline Author fax: & $412-647-2455$ \\
\hline Author phone: & $412-647-6089$ \\
\hline & \\
\hline Affiliation(s) at time of authorship: & \\
\hline Title or Position & Associate Professor and Director \\
\hline Department & $\begin{array}{l}\text { Department of Audiology and Hearing } \\
\text { Aids, } \\
\text { Communication Science and Disorders }\end{array}$ \\
\hline Institution & $\begin{array}{l}\text { University of Pittsburgh, } \\
\text { University of Pittsburgh Medical Center }\end{array}$ \\
\hline Street address & $\begin{array}{l}\text { Audiology and Hearing Aids, } \\
\text { Eye and Ear Institute, } \\
\text { 203 Lothrop Street }\end{array}$ \\
\hline City & Pittsburgh \\
\hline State/Province & Pennsylvania \\
\hline Postal code & $\mathbf{1 5 2 1 3}$ \\
\hline Country & U.S.A. \\
\hline & \\
\hline & \\
\hline
\end{tabular}




\begin{tabular}{|l|l|}
\hline & \\
\hline $\begin{array}{l}\text { Current affiliation(s):Repeat if same as } \\
\text { affiliations at the time of authorship: }\end{array}$ & \\
\hline Title or Position & Associate Professor and Director \\
\hline Department & $\begin{array}{l}\text { Department of Audiology and Hearing } \\
\text { Aids, } \\
\text { Communication Science and Disorders }\end{array}$ \\
\hline Institution & $\begin{array}{l}\text { University of Pittsburgh, } \\
\text { University of Pittsburgh Medical Center }\end{array}$ \\
\hline Street address & $\begin{array}{l}\text { Audiology and Hearing Aids, } \\
\text { Eye and Ear Institute, } \\
\text { 203 Lothrop Street }\end{array}$ \\
\hline City & Pittsburgh \\
\hline State/Province & Pennsylvania \\
\hline Postal code & 15213 \\
\hline Country & U.S.A. \\
\hline & \\
\hline & $\mathbf{2}$ \\
\hline Author Number: & Amanda \\
\hline Author first name or initial: & \\
\hline Author middle initial: & Ortmann \\
\hline Author last name: & M.A. \\
\hline Suffix to last name: & Please Provide Email Address \\
\hline Degrees: & 4l2-647-2455 \\
\hline Honorific: & 412 -647-6089 \\
\hline Author e-mail address: & \\
\hline Author fax: & Please Provide Title \\
\hline Author phone: & Department of Audiology and Hearing \\
\hline & Aids \\
\hline Affiliation(s) at time of authorship: & Pittsburgh of Pittsburgh Medical Center \\
\hline Title or Position & $\begin{array}{l}\text { Audiology and Hearing Aids, } \\
\text { Eye and Ear Institute, } \\
\mathbf{2 0 3} \text { Lothrop Street }\end{array}$ \\
\hline Department & Pittsburgh \\
\hline Institution & Pennsylvanis \\
\hline Street address & $\mathbf{1 5 2 1 3}$ \\
\hline City & U.S.A. \\
\hline State/Province & \\
\hline Postal code & $\begin{array}{l}\text { Current affiliation(s):Repeat if same as } \\
\text { affiliations at the time of authorship: }\end{array}$ \\
\hline Country & \\
\hline & \\
\hline
\end{tabular}




\begin{tabular}{|l|l|}
\hline Title or Position & Please Provide Title \\
\hline Department & Department of Audiology and Hearing Aids \\
\hline Institution & $\begin{array}{l}\text { University of Pittsburgh Medical Center } \\
\text { Pittsburgh }\end{array}$ \\
\hline Street address & $\begin{array}{l}\text { Audiology and Hearing Aids, } \\
\text { Eye and Ear Institute, } \\
\text { 203 Lothrop Street }\end{array}$ \\
\hline City & Pittsburgh \\
\hline State/Province & Pennsylvanis \\
\hline Postal code & 15213 \\
\hline Country & U.S.A. \\
\hline & \\
\hline Mailing address: & $\begin{array}{l}\text { Department of Audiology and Hearing } \\
\text { Aids, } \\
\text { Communication Science and Disorders }\end{array}$ \\
\hline Department & $\begin{array}{l}\text { University of Pittsburgh } \\
\text { University of Pittsburgh Medical Center }\end{array}$ \\
\hline Institution or Company & $\begin{array}{l}\text { Audiology and Hearing } \text { Aids, } \\
\text { Eye and Ear Institute, } \\
\text { 203 Lothrop Street }\end{array}$ \\
\hline Street address & Please Provide Suite No. \\
\hline Suite, floor, room no. & Pittsburgh \\
\hline City & Pennsylvania \\
\hline State/Province & $\mathbf{1 5 2 1 3}$ \\
\hline Postal code & U.S.A. \\
\hline Country & \\
\hline & \\
\hline Recipient of R1 proofs: & palmercv@upmc.edu \\
\hline e-mail address to receive proofs: & 412-647-2455 \\
\hline Fax to receive proof: & Please Provide \\
\hline Mailing address to receive proof: &
\end{tabular}

